\title{
Cognitive function is associated with prison behaviour among women in prison but not with subjective perception of adjustment to prison
}

NUNO B. F. ROCHA ${ }^{1,2}$, DUARTE A. FONSECA ${ }^{1}$, ALINA B. MARQUES ${ }^{3}$, SUSANA A. ROCHA ${ }^{4}$ AND PETER N. S. HOAKEN ${ }^{5}$, ${ }^{1}$ Escola Superior de Tecnologia da Saúde, Instituto Politécnico do Porto, Vila Nova de Gaia, Portugal; ${ }^{2}$ Universidade do Porto, Faculdade de Psicologia e de Ciências da Educação, Porto, Portugal; ${ }^{3}$ Estabelecimento Prisional Especial de Santa Cruz do Bispo, Porto, Portugal; ${ }^{4}$ Instituto Superior de Contabilidade e Administração, Instituto Politécnico do Porto, Matosinhos, Portugal; ${ }^{5}$ Faculty of Social Science, Western University, London, Ontario, Canada

\section{ABSTRACT}

Background There is considerable evidence that aspects of cognitive function, especially executive function, are associated with antisocial behaviour and violence, but most research to date has measured current cognition and previous criminal behaviour. Furthermore, this research has been conducted almost exclusively with male offenders.

Aim The aim of this study is to examine relationships between a wide range of cognitive functions and behaviours among women in prison. Our hypotheses were that cognitive functioning would be associated with both more-or-less contemporaneously observed behaviour problems and self-rated adjustment to the environment.

Method Forty-five drug-free imprisoned female offenders were individually assessed on a battery of cognitive measures. Prison staff rated their behaviour on the Prison Behaviour Rating Scale and the women rated their own sense of adjustment to the environment on the Prison Adjustment Questionnaire.

Results Stepwise hierarchical regressions indicated that attention was independently associated with behaviours reflecting tension, depression, isolation, fear, victimisation and worry, whereas processing speed was independently associated with behaviours reflecting lack of energy, mental slowness and lack of awareness of the surrounding environment and total Prison Adjustment Questionnaire score. There was no relationship between cognitive functioning and subjective perception of adjustment to prison. 
Conclusions and Implications for Practice and Future Research Results indicate that cognition contributes to some of the behavioural problems displayed by inmates in the prison context. Future studies should evaluate the role of programmes to improve cognitive processes in also improving prison behaviour and also test for continuities and discontinuities with post-release integrative success. Copyright (c) 2014 John Wiley Eु Sons, Ltd.

\section{Introduction}

Understanding the correlates of dysfunctional behaviour in a prison setting is important for better understanding how inmates will adapt and perform there and how this may relate, if at all, to how they will eventually reintegrate into society.

Disturbed behaviour in prisons may arise for many different reasons and/or have multiple causes and contributory factors. Much research focuses on violence, but this is only one facet of disturbed prison behaviour. A range of situational variables, such as management policies, physical resources, staff characteristics, security levels or overcrowding, may exert a considerable influence on behaviour (Gadon et al., 2006) but cannot explain all behavioural disruptions. A wide range of individual characteristics have been shown to be associated with prison violence, including age, educational level, criminal history, length of incarceration, prior convictions and psychological variables, such as personality characteristics, psychopathology or self-esteem (Schenk and Fremouw, 2012).

An extensive body of research has now shown that cognitive deficits may be a major correlate of dysfunctional and/or criminal behaviours (Séguin et al., 1995; Morgan and Lilienfeld, 2000; Ogilvie et al., 2011). Cognitive problems, particularly executive dysfunction, have been associated with the severity and frequency of violent crime (Hancock et al., 2010), whereas recidivism is characteristic of individuals with severe executive dysfunction (Barbosa and Monteiro, 2008; Ross and Hoaken, 2011). Furthermore, brain injury, which is more prevalent among incarcerated populations (Farrer and Hedges, 2011), may underpin both reduced executive function and increased aggression and anger (Slaughter et al., 2003), but little is known about the effect of cognition on behaviour and adjustment specifically within the prison setting.

One theory of criminality that implicates cognitive deficits in offender behaviour patterns suggests two different antisocial trajectories: life-course persistent and adolescence-limited (Moffitt, 1993), with subsequent evidence that neuropsychological problems, including deficits in executive functions, are characteristic of life-course persistent offenders, or individuals who begin offending early, offend for a large duration of their lives, and who engage in more serious and violent forms of offending (Moffitt and Caspi, 2001; Raine et al., 2005). It seems likely that people in prison, who are disproportionately likely to be persistent offenders, are more likely than not to have relevant cognitive impairments and may thus be 
vulnerable to poor adjustment to the prison setting and more disrupted behaviours there.

Existing research on the neuropsychology of incarcerated offenders has tended to rely on samples of men. The few studies of cognition among female offenders show that they too tend to have neuropsychological dysfunction (Coolidge et al., 2011) and that such dysfunction is associated with aggression (Daoust et al., 2006). Neuropsychological data in these studies were, however, obtained from self-reported function, which constitutes a major methodological limitation (see Dunning et al., 2004, for a review).

Given the paucity of such research among female prisoners but its likely importance of research in this field, our aim was to examine cognitive functioning among female offenders and its relationship to their behaviour in prison. We hypothesised that cognitive functioning in women prisoners would be associated with both behaviour in the prison and also their own perceptions of adjustment to the prison environment.

\section{Methods}

The sample

Participants were recruited from the special prison facility Santa Cruz do Bispo, a prison for women in the north of Portugal, drawing from all over Portugal and which houses 282 women at the moment. Length of sentence served there ranges from 1 month to 25 years. It has a capacity to hold about 350 women at any one time. Inclusion criteria for this study were as follows: (a) fluency in the Portuguese language, (b) literacy and (c) no drug dependence. Fifty-nine women of a possible $x$ who were eligible were invited to participate in the study based on these criteria; 14 declined to participate. All 45 participants provided written, informed consent. All participants were recruited from a broader study designed to implement cognitive remediation for female offenders, approved by the Portuguese DirectorateGeneral of Prison Services.

\section{Measures}

Cognitive assessments included measures of executive function, verbal learning and memory, and verbal working memory and attention. Rather than using a composite score of cognition, we used specific components of each measure to quantify specific features of cognitive function.

The Trail Making Test (TMT) (Reitan, 1992; Reitan and Wolfson, 1995) is a two-part paper and pencil test that evaluates attention and speed of processing (Part A) and cognitive flexibility and set shifting (Part B). Part A requires connecting numbered circles as quickly as possible, beginning at the number 1 and proceeding in a numerical sequence. Part B requires switching between numbers 
and letters by connecting numbers and characters. The scores are the number of seconds taken to complete each task (lower scores reveal better functioning).

The Neuropsychological Assessment Battery (NAB) Mazes Test (Nuechterlein and Green, 2006) is designed to assess problem solving. It requires completion of seven mazes of gradually increasing difficulty. Participants are rewarded for solving the mazes rapidly and are timed. The shorter the completion time, the higher is the number of points earned.

The Rule Shift Cards (RSC) test from the Behavioural Assessment Dysexecutive Syndrome (Wilson et al., 1996) was used to assess perseverative tendencies and the ability to change from one pattern of responding to another. This test requires responses to stimuli (red or black playing cards) according to one of two rules that are presented consecutively in two different trials: in the first trial, the participant has to answer 'yes' to a red card and 'no' to a black card; in the second, the requirement is to indicate whether or not a card matches the colour of the card immediately preceding it. Performance is rated from 0 (severely deficient) to 4 (normal performance), allowing for errors made and time taken to complete the task.

The Modified Six Elements (MSE) from the Behavioural Assessment Dysexecutive Syndrome (Wilson et al., 1996) consists of three different tasks divided in two parts ( $\mathrm{A}$ and $\mathrm{B}$, for a total of six subtasks) and to assess planning and organisational ability. Participants are instructed to attempt each of the six subtasks within 10 minutes and that no two parts of the same task can be completed consecutively. The rules are given to participants to consult as necessary during the test. Performance is rated from 0 (severely deficient) to 4 (normal performance), taking into account if all tasks were started, no rule was broken and the participant did not exceed 271 seconds on any one of the six tasks.

The Hopkins Verbal Learning Test-Revised (HVLT-R; Benedict et al., 1998) is an assessment of verbal learning and memory which consists of 12 words within three semantic groups that are orally presented over three immediate recall trials, followed by a delayed recall trial (in this study we used a 20-minute interval) and a recognition trial. This recognition trial consists of a randomised list that includes the 12 target words and 12 non-target words. We computed the following scores: total recall (TR; sum of the three immediate recall trials), delayed recall (DR; total words recalled at the delayed recall trial), and the recognition discrimination index (RDI; true positives minus false positives in the recognition trial).

The Letter Number Sequencing (LNS) task (Wechsler, 2008) is a measure of verbal working memory that requires the participant to listen to a presentation of alternating letters and digits. After each trial, the participant is asked to repeat the numbers first in ascending order and then the letters in alphabetical order. Each item contains three trials with the same number of digits and letters but composed of different combinations of them. Raw score ranging from 0 to 21 points were computed.

The 12 Cancellation Test (Brickenkamp and Zillmer, 2007) is a paper and pencil cancellation test composed of 14 lines with 47 letters each which is intended 
to measure participants' selective attention and visual scanning ability. Each participant is instructed to scan across each line with a time limit of 20 seconds per line and to cross out targets that include a 'd' and two dashes (alternatively above, below, or separated, one mark above and one mark below). Non-target distractor stimuli consist of a $d$ with one or more than two dashes or a $p$ with any number of dashes. The scores analysed were total test effectiveness (TTE; the total number of items processed minus error scores) and concentration performance (CP; the number of correctly crossed out items minus errors of commission).

In addition to the cognitive assessments, participants were asked to rate their own perceptions of their adjustment to the prison setting and ratings of their behaviour were obtained from correctional staff.

The Prison Adjustment Questionnaire (PAQ; Wright, 1985) was used to quantify the prisoners' sense of their adjustment to the prison environment. It is a two-part, 30-item questionnaire covering common adjustment problems during incarceration. In this study, we used just the first segment (20 items) designed to assess adjustment in prison compared with adjustment in the community. Participants are asked to compare how they are doing in prison with how they functioned before prison. If their adjustment is worse while in prison, then they are asked to indicate the severity and frequency of the problems. In line with previous research with female prisoners (Warren et al., 2004), we computed a distress and a conflict score; higher scores represent worse adjustment.

The Prison Behaviour Rating Scale (PBRS; Cooke, 1998) is a 36-item measure designed to assess psychological features and disturbed behaviour in prison settings. Correctional staff rate using a 4-point scale ( 0 - never/rarely, 1 - sometimes, 2 - often, and 3 - most of the time). The items are in three subscales: anti-authority, which reflects hostile behaviour, tendency to break rules, aggression towards staff and a lack of concern for others; anxious-depressed, which reflects tension, emotional volatility, fear, victimisation and worry; and dull-confused, which reflects lack of energy, mental slowness and lack of awareness of the surrounding environment. Higher scores represent more deviant behaviours.

\section{Procedures}

All participants provided written, informed consent. Each then completed the cognitive measures and the PAQ in one 60-90-minute session or in two 45-minute sessions, depending on the inmate schedule or fatigue. Correctional staff from the Education and Teaching Service rated the PBRS. All had daily contact with inmates.

\section{Data analysis}

Pearson product-moment correlation coefficients were calculated to determine the associations between cognition and prison behaviour and subjective perception of adjustment. Hierarchical multiple regressions were conducted to evaluate the 
predictive value of cognition on prison behaviour and adjustment, while controlling for demographic (age and educational level) and criminal variables (prior incarcerations, punishments and sentence length). At each step in hierarchical modelling, the method of stepwise entering for each block or set of variables was performed. The statistical analyses were carried out using IBM SPSS Statistics 20.

\section{Results}

Table 1 shows the demographic and criminal characteristics of the 45 participants. They were aged between 21 and 62 years (mean 36.67 years; SD = 7.75). Thirty-two of the women had been imprisoned for the first time and 13 were repeat offenders; 41 were already sentenced and 4 were on remand awaiting sentence. No data were available for participants' psychiatric or medical history. Table 2 shows the scores on the cognitive tests.

Pearson product-moment correlation coefficients between cognitive variables and behaviour and adjustment to prison are displayed in Table 3. Generally, negative correlations mean that the lower the scores on cognitive measures, the higher were the behavioural difficulties as assessed by the PBRS. The exception lies in the scores on the TMT A and B, given that a higher score reflects decreased speed of processing.

There was no correlation between self-rated adjustment to the prison environment (according to the PAQ) and any cognitive measure. By contrast, staff ratings of overall prisoner behaviour suggestive of difficulties, according to PBRS total scores, correlated with scores on $\mathrm{d} 2$, suggestive of attention skills, and on the NAB Mazes, indicative of problem solving skills, but in the opposite direction on the TMT A, which indicates speed of processing. Correlations between scores on the anxious-depression subscale and cognitive measures showed an almost identical pattern. Dull-confusion subscale scores were negatively associated with cognitive ratings indicative of learning and working memory capacity (HVLT-R and LNS), attention (d2), problem solving (NAB Mazes), and capacity for planning (MSE) and positively correlated to processing speed and cognitive flexibility (TMT A and B). Anti-authority attitudes, as indicated by the PBRS subscale, were not associated with any cognitive measures at all.

A number of regression analyses were conducted with the different observed prisoner behaviours as the dependent variables, and cognitive measures that had shown a significant relationship with these at the bivariate level as the independent variables. Potential confounding was allowed for by adding age, educational level, prior incarcerations, punishments and sentence length as additional independent variables to each model tested. Table 4 shows the full results of each analysis.

In the first regression, from the first block, we found that educational level was significantly associated with the PBRS total score $(\beta=-0.350 ; p<0.05)$. The 
Table 1: Summary of participant characteristics

\begin{tabular}{|c|c|}
\hline & $N$ or $M(S D)$ \\
\hline Age (years) & $36.67(7.75)$ \\
\hline \multicolumn{2}{|l|}{ Marital status } \\
\hline Married & 19 \\
\hline Single & 14 \\
\hline Divorced/separated & 9 \\
\hline Deceased spouse & 3 \\
\hline Educational level (years) & $8.71(3.28)$ \\
\hline \multicolumn{2}{|l|}{ Crime $^{1}$} \\
\hline Child sexual abuse & 2 \\
\hline Aggression & 3 \\
\hline Swindling and fraud/embezzlement & 4 \\
\hline Coercion & 1 \\
\hline Possession of firearms & 2 \\
\hline Murder & 3 \\
\hline Disobedience & 2 \\
\hline Driving without a licence & 1 \\
\hline Dangerous driving & 1 \\
\hline Hide a dead body & 1 \\
\hline Breach of confidence & 1 \\
\hline Child pornography & 1 \\
\hline Theft/robbery/aggravated burglary & 15 \\
\hline Drug trafficking & 23 \\
\hline \multicolumn{2}{|l|}{ Penal situation } \\
\hline Remand detention & 4 \\
\hline Convicted & 41 \\
\hline \multicolumn{2}{|l|}{ Prior incarcerations } \\
\hline No & $32(71.11)$ \\
\hline Yes & $13(28.89)$ \\
\hline Sentence length ${ }^{2}$ (months) & $74,71(42.29)$ \\
\hline Punishments ${ }^{3}$ & $0.67(1.91)$ \\
\hline
\end{tabular}

\footnotetext{
${ }^{1}$ The sum of the types of crimes is 60 because 14 participants committed more than one crime. ${ }^{2}$ Means for inmates already sentenced $(n=41)$.

${ }^{3}$ Punishments refer to the number of times the inmate was punished for incorrect behaviour and/or breach of the prison rules.
}

resultant model accounted for $12.3 \%$ of the variance in the dull-confused scale and the model showed a good fit $(F=5.45, p<0.05)$. From the second block of cognitive variables, the speed of processing score according to the TMT A was entered into the model. The final model $(F=5.24, p<0.05)$ explained $21.6 \%$ of the variance, with TMT A $(\beta=0.337 ; p<0.05)$ a significant associate of behaviour. When TMT A was added to the model in this second step, educational level was no longer a significantly related $(\beta=-0.209 ; p=0.194)$. This means that for every 1 -point decrease in $\mathrm{d} 2$ score, anxious depression scores increased by 0.337 . 
Table 2: Cognitive tests scores

\begin{tabular}{llrc}
\hline Cognitive variables & & Mean & Standard deviation \\
\hline HVLT-R & TR & 22.667 & 4.4262 \\
& DR & 7.956 & 2.056 \\
& RDI & 11.422 & 0.965 \\
TMT & A & 67.356 & 57.380 \\
& B & 178.333 & 107.477 \\
NAB Mazes & & 10.133 & 6.663 \\
LNS & & 7.311 & 2.466 \\
d2 & CP & 110.000 & 49.491 \\
& TTE & 302.111 & 97.696 \\
BADS RSC & & 2.622 & 1.267 \\
BADS MSE & & 2.511 & 1.199 \\
\hline
\end{tabular}

Note: HVLT-R - Hopkins Verbal Learning Test-Revised; TR - Total Recall; DR - Delay Recall; RDI Recognition Discrimination Index; TMT - Trail Making Test; NAB Mazes - Neuropsychological Assessment Battery Mazes Test; LNS - Letter Number Sequence; d2 - d2 Cancellation Test; CP Concentration Performance; TTE - Total Test Effectiveness; BADS - Behavioural Assessment Dysexecutive Syndrome RSC - Rule Shift Card; BADS MSE - Modified Six Elements.

None of the first block of variables had a significant relationship to anxious depression. For that reason, the variables were not included in the regression analysis. With all cognitive variables in the model, we confirmed that only attentional scores according to the $\mathrm{d} 2$ rating were independently related to anxious-depression. The model accounted for $12.3 \%$ of the variance on the anxious-depressed scale and the model showed a good fit $(F=5.49, p<0.05)$. We estimated that for every 1 -point decrease in $\mathrm{d} 2$ score, anxious depression scores increased by 0.351 .

Finally, from the first block, we found that educational level was significantly related to the dull-confusion scale of the PBRS. The resulting model accounted for $22.4 \%$ of the variance in the dull-confused scale and the model showed a good fit $(F=11.26, p<0.01)$. From the second block of cognitive variables, the TMT A entered the model and improved the fit of the model. The final model $(F=11.48, p<0.00)$ explained $37.7 \%$ of the variance and both educational level $(\beta=-0.294 ; p<0.05)$ and TMT A $(\beta=0.430 ; p<0.01)$ were significantly and independently associated. This means that for every 1 -point increase in TMT A score, the dull-confused scale score increased by 0.430 .

\section{Discussion}

According to the expectations raised by our hypothesis, we found evidence indicating that cognitive functioning is contributing to some of the behavioural problems displayed by inmates while in prison. Thus, we extended the idea that cognitive functions are important for observed feelings and/or actions 


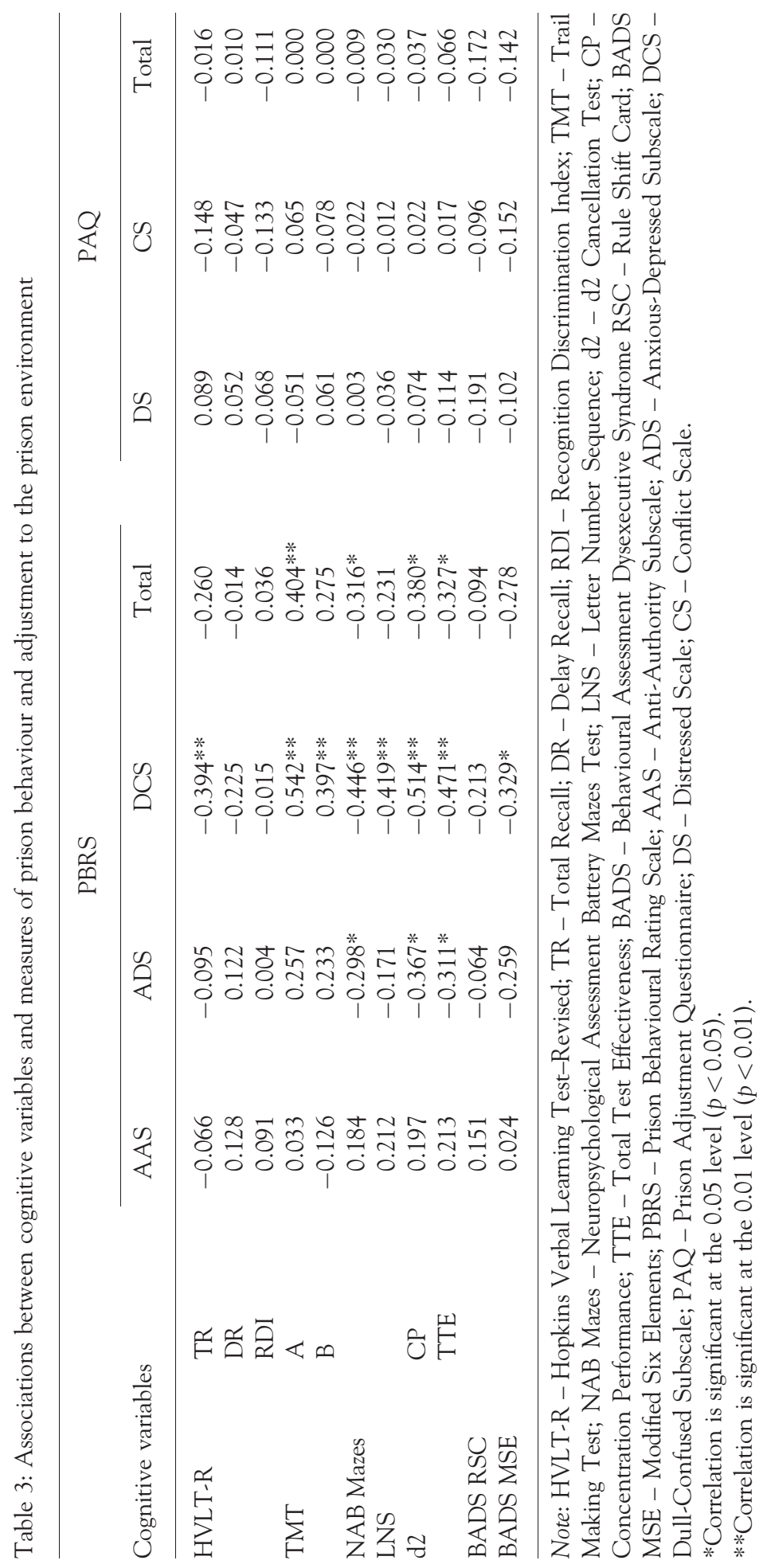


Table 4: Results of hierarchical regression analysis

\begin{tabular}{llccccc}
\hline Independent variable & \multicolumn{1}{c}{ Predictor } & $\beta$ & $t$ & $p$ & $R$ & $R^{2}$ \\
\hline PBRS Anxious-Depressed & d2 - CP & -0.351 & -2.343 & 0.024 & 0.351 & 0.123 \\
PBRS Dull-confused & Step 1 & & & & 0.473 & 0.224 \\
& Educational level & -0.473 & -3.356 & 0.002 & & \\
& Step 2 & & & & 0.614 & 0.377 \\
& Educational level & -0.294 & -2.081 & 0.044 & & \\
& TMT A & 0.430 & 3.049 & 0.004 & & \\
PBRS total score & Step 1 & & & & 0.350 & 0.123 \\
& Educational level & -0.350 & -2.334 & 0.025 & & \\
& Step 2 & & & & 0.465 & 0.216 \\
& Educational level & -0.209 & -1.323 & 0.194 & & \\
& TMT A & 0.337 & 2.130 & 0.040 & & \\
\hline
\end{tabular}

Note: PBRS - Prison Behavior Rating Scale; d2 CP - d2 Test Concentration Performance; TMT A Trail Making Test part A.

(Bell-McGinty et al., 2002; Fett et al., 2011; Depp et al., 2012) to the prison context. Two cognitive functions were particularly important in their association with prison behaviour: attention and processing speed.

Attention ( $\mathrm{d} 2$ ) was the strongest associate of behaviours reflecting tension, depression, isolation, fear, victimisation and worry. Attention deficits have previously been reported in adults and children with problems in emotional regulation (Arnsten and Rubia, 2012; Retz et al., 2012; Surman et al., 2013) and after major trauma (Stein et al., 2002; Connors et al., 2012; Sciberras et al., 2012; Schlack et al., 2013). Inattention has separately been noted as common among incarcerated offenders, including female prisoners (Rosler et al., 2004; Rosler et al., 2009; Cahill et al., 2012). It is possible that prisoners with higher levels of emotional disturbances may allocate considerable attentional resources to cope with emotional distress, leaving fewer attentional resources to attend to relevant tasks or distinguish and disregard irrelevant information.

Processing speed (TMT A) was the strongest correlate of behaviours reflecting lack of energy, mental slowness and lack of awareness of the surrounding environment, and the strongest predictor of PBRS total score. Slowed processing speed, as measured by the trail making test in Part A, also has been reported in offenders and people with anti-social tendencies (Morgan and Lilienfeld, 2000). Processing speed is fundamental to the quick and effective completion of a goal (Turken et al., 2008). In that sense, impaired processing speed may give the inmate an appearance of slowness and lack of engagement with the environment. It can also lead to difficulties understanding and attending to complex situations and may compromise the information processing abilities necessary for timely interpretations of social interactions. Processing speed and attention are, however, functions that are highly correlated with executive functions (Salthouse, 2005; Diamond, 2013). Furthermore, some aspects of processing speed and attentional 
control are mediated by executive functions. Although still debated, many experts in the field agree that executive function is a non-unitary construct, made up of related but separate cognitive abilities (Miyake et al., 2000; de Frias et al., 2006). In that sense, and given that several measures of executive functioning were correlated with prison behaviour, our findings leave unanswered the question of whether executive function specifically or cognitive functions more generally better predicts the in-prison behaviour of female inmates. Nevertheless, it is evident that cognitive impairments interfere significantly with their in-prison behaviour.

Contrary to hypotheses, we found no significant associations between cognition and self-rated adjustment to prison. There are two potential explanations for this finding. First, adjustment to imprisonment was measured by self-report, which is subjective and therefore reflects only one aspect of it (Dunning et al., 2004). In a psychiatric population, it has been shown that cognitive measures are positively correlated with objective measures of quality of life, but either unrelated to or negatively correlated with subjective quality of life measures (Tolman and Kurtz, 2012). Second, the PAQ was originally designed to evaluate adjustment to prison in comparison with prior life in the community. This can result in a report of adjustment that does not reflect how well the inmate has adjusted to prison environment per se, but instead how they are doing when compared with their prior life conditions.

This preliminary study has a number of limitations, including small sample size and absence of follow-up. Its cross-sectional nature prevents the establishment of causal associations. We did not control for psychiatric co-morbidity or general intellectual disability, which may be potential confounders, mainly because of the prevalence of cognitive impairments among people with psychiatric illness, including depression (Rock et al., 2013).

Nevertheless, our results highlight potentially important relationships between cognition and behaviours in prison, which may have implications for managing such women safely and for current efforts towards correctional rehabilitation. There is evidence that neurocognitive deficits are not being appropriately addressed by most correctional rehabilitation programmes (Ross, 2012). Our findings suggest that assessment and perhaps assistance with aspects of cognition could help prisoners to use those skills to engage in remediation programmes and improve their behaviour. One important question that consequently arises is whether it is possible to improve these cognitive functions. In studies with people with neuropsychiatric disorders such as schizophrenia, it has been shown that cognitive remediation has the potential to produce durable improvements in cognition (Wykes et al., 2011).

\section{References}

Arnsten AF, Rubia K (2012) Neurobiological circuits regulating attention, cognitive control, motivation, and emotion: Disruptions in neurodevelopmental psychiatric disorders. Journal of the American Academy of Child and Adolescent Psychiatry 51: 356-367. 
Barbosa M, Monteiro L (2008) Recurrent criminal behavior and executive dysfunction. The Spanish Journal of Psychology 11: 259-265.

Bell-McGinty S, Podell K, Franzen M, Baird A, Williams M (2002) Standard measures of executive function in predicting instrumental activities of daily living in older adults. International Journal of Geriatric Psychiatry 17: 828-834.

Benedict RHB, Schretlen D, Groninger L, Brandt J (1998) Hopkins Verbal Learning Test-Revised: Normative data and analysis of inter-form and test-retest reliability. The Clinical Neuropsychologist 12: 43-55.

Brickenkamp R, Zillmer E (2007) D2: Teste de Atenção (d2 Test of Attention; Test d2 Aufmerksamkeits-Belastungs-Test) Handanweisung). Lisboa: Cegoc.

Cahill BS, Coolidge FL, Segal DL, Klebe KJ, Marle PD, Overmann KA (2012) Prevalence of ADHD and its subtypes in male and female adult prison inmates. Behavioral Sciences $\mathbb{E}$ the Law 30: 154-166.

Connors LL, Connolly J, Toplak ME (2012) Self-reported inattention in early adolescence in a community sample. Journal of Attention Disorders 16: 60-70.

Cooke D (1998) The development of the Prison Behavior Rating Scale. Criminal Justice and Behavior 25: 482-506.

Coolidge F, Marle P, Horn S, Segal D (2011) Clinical syndromes, personality disorders, and neurocognitive differences in male and female inmates. Behavioral Sciences and the Law 29: 741-751.

Daoust S, Loper A, Magaletta P, Diamond P (2006) Neuropsychological dysfunction and aggression among female federal inmates. Psychological Services 3: 88-96.

Depp C, Mausbach B, Harmell A, Savla G, Bowie C, Harvey P, Patterson T (2012) Meta-analysis of the association between cognitive abilities and everyday functioning in bipolar disorder. Bipolar Disorders 14: 217-226.

Diamond A (2013) Executive functions. Annual Review of Psychology 64: 135-168.

Dunning D, Heath C, Suls J (2004) Flawed self-assessment: Implications for health, education, and the workplace. Psychological Science in the Public Interest 5: 69-106.

Farrer T, Hedges D (2011) Prevalence of traumatic brain injury in incarcerated groups compared to the general population: A meta-analysis. Progress in Neuro-Psychopharmacology and Biological Psychiatry 35: 390-394.

Fett A, Viechtbauer W, Dominguez M, Penn D, van Os J, Krabbendam L (2011) The relationship between neurocognition and social cognition with functional outcomes in schizophrenia: A meta-analysis. Neuroscience and Biobehavioral Reviews 35: 573-588.

de Frias CM, Dixon RA, Strauss E (2006) Structure of four executive functioning tests in healthy older adults. Neuropsychology 20: 206-214.

Gadon L, Johnstone L, Cooke D (2006) Situational variables and institutional violence: A systematic review of the literature. Clinical Psychology Review 26: 515-534.

Hancock M, Tapscott J, Hoaken P (2010) The role of executive dysfunction in predicting frequency and severity of violence. Aggressive Behavior 36: 338-349.

IBM Corp. (2011) IBM SPSS Statistics for Windows, Version 20.0. Armonk, NY: IBM Corp.

Miyake A, Friedman NP, Emerson MJ, Witzki AH, Howerter A, Wager TD (2000) The unity and diversity of executive functions and their contributions to complex 'Frontal Lobe' tasks: A latent variable analysis. Cognitive Psychology 41: 49-100.

Moffitt TE (1993) Adolescence-limited and life-course-persistent antisocial behavior: a developmental taxonomy. Psychological Review 100: 674-701.

Moffitt TE, Caspi A (2001) Childhood predictors differentiate life-course persistent and adolescence-limited antisocial pathways among males and females. Development and Psychopathology 13: 355-375.

Morgan A, Lilienfeld S (2000) A meta-analytic review of the relation between antisocial behavior and neuropsychological measures of executive function. Clinical Psychology Review 20: $113-136$. 
Nuechterlein K, Green M (2006) MCCB: MATRICS Consensus Cognitive Battery. Los Angeles: MATRICS Assessment Inc.

Ogilvie J, Stewart A, Chan R, Shum D (2011) Neuropsychological measures of executive function and antisocial behavior: A meta-analysis. Criminology 49: 1063-1107.

Raine A, Moffitt TE, Caspi A, Loeber R, Stouthamer-Loeber M, Lynam D (2005) Neurocognitive impairments in boys on the life-course persistent antisocial path. Journal of Abnormal Psychology 114: 38-49.

Reitan R (1992) Trail Making Test: Manual for Administration and Scoring. Tuscon, AZ: Reitan Neuropsychological Laboratories.

Reitan R, Wolfson D (1995) Category Test and Trail Making Test as measures of frontal lobe functions. The Clinical Neuropsychologist 9: 50-56.

Retz W, Stieglitz RD, Corbisiero S, Retz-Junginger P, Rosler M (2012) Emotional dysregulation in adult ADHD: What is the empirical evidence? Expert Review of Neurotherapeutics 12: 1241-1251.

Rock PL, Roiser JP, Riedel WJ, Blackwell AD (2013) Cognitive impairment in depression: A systematic review and meta-analysis. Psychological Medicine 29: 1-12.

Rosler M, Retz W, Retz-Junginger P, Hengesch G, Schneider M, Supprian T, Schwitzgebel P, Pinhard K, Dovi-Akue N, Wender P, Thome J (2004) Prevalence of attention deficit/hyperactivity disorder (ADHD) and comorbid disorders in young male prison inmates. European Archives of Psychiatry and Clinical Neuroscience 254: 365-371.

Rosler M, Retz W, Yaqoobi K, Burg E, Retz-Junginger P (2009) Attention deficit/hyperactivity disorder in female offenders: Prevalence, psychiatric comorbidity and psychosocial implications. European Archives of Psychiatry and Clinical Neuroscience 259: 98-105.

Ross E (2012) Are offence-focused correctional rehabilitation programs affecting inmates' executive cognitive functions? Unpublished Doctoral Dissertation, University of Western Ontario, Ontario.

Ross E, Hoaken P (2011) Executive cognitive functioning abilities of male first time and return Canadian federal inmates. Canadian Journal of Criminology and Criminal Justice 53: 377-403.

Salthouse TA (2005) Relations between cognitive abilities and measures of executive functioning. Neuropsychology 19: 532-545.

Schenk A, Fremouw W (2012) Individual characteristics related to prison violence: A critical review of the literature. Aggression and Violent Behavior 17: 430-442.

Schlack R, Ravens-Sieberer U, Petermann F (2013) Psychological problems, protective factors and health-related quality of life in youth affected by violence: The burden of the multiply victimised. Journal of Adolescence 36: 587-601.

Sciberras E, Ohan J, Anderson V (2012) Bullying and peer victimisation in adolescent girls with attention-deficit/hyperactivity disorder. Child Psychiatry and Human Development 43: 254-270.

Séguin JR, Pihl RO, Harden PW, Tremblay RE, Boulerice B (1995) Cognitive and neuropsychological characteristics of physically aggressive boys. Journal of Abnormal Psychology 104: 614-624.

Slaughter B, Fann J, Ehde D (2003) Traumatic brain injury in a county jail population: Prevalence, neuropsychological functioning and psychiatric disorders. Brain Injury 17: 731-741.

Stein MB, Kennedy CM, Twamley EW (2002) Neuropsychological function in female victims of intimate partner violence with and without posttraumatic stress disorder. Biological Psychiatry 52: 1079-1088.

Surman CB, Biederman J, Spencer T, Miller CA, McDermott KM, Faraone SV (2013) Understanding deficient emotional self-regulation in adults with attention deficit hyperactivity disorder: A controlled study. Attention Deficit and Hyperactivity Disorders 5: 273-281.

Tolman A, Kurtz M (2012) Neurocognitive predictors of objective and subjective quality of life in individuals with schizophrenia: A meta-analytic investigation. Schizophrenia Bulletin 38: 304-315.

Turken A, Whitfield-Gabrieli S, Bammer R, Baldo JV, Dronkers NF, Gabrieli JD (2008) Cognitive processing speed and the structure of white matter pathways: Convergent evidence from normal variation and lesion studies. NeuroImage 42: 1032-1044.

Warren JI, Hurt S, Loper AB, Chauhan P (2004) Exploring prison adjustment among female inmates: Issues of measurement and prediction. Criminal and Justice Behavior 31: 624-645. 
Wechsler D (2008) Wechsler Adult Intelligence Scale (Escala de Inteligência de Wechsler para Adultos). Lisboa: Cegoc.

Wilson B, Alderman N, Burgess P, Emslie H, Evans J (1996) Behavioural Assessment of the Dysexecutive Syndrome. London: Thames Valley Test Company.

Wright K (1985) Improving correctional classification through a study of the placement of inmates in environmental settings. Final Report, National Institute of Justice Grant, 83-IJ-CX-0011, United States Department of Justice, Washington.

Wykes T, Huddy V, Cellard C, McGurk S, Czobor P (2011) A meta-analysis of cognitive remediation for schizophrenia: Methodology and effect sizes. American Journal of Psychiatry 168: 472-485.

Address correspondence to: Dr Nuno Rocha, Escola Superior de Tecnologia da Saúde, Instituto Politécnico do Porto, Rua Valente Perfeito 322, 4400-330, Vila Nova de Gaia, Portugal. Email: nrocha@eu.ipp.pt 